\title{
Proceeding
}

Supplementary Issue: Summer Conferences of Sports Science. $8^{\text {th }}$ International Workshop and Conference of the International Society of Performance Analysis of Sport (ISPAS), 11-1 th of September 2019 (Budapest, Hungary) "Technology meets Practice and Science".

\section{Differences in technical-tactical indicators of Karate Kumite between the World Championship in Tokyo 2008 and Madrid 2018}

\author{
TIHOMIR VIDRANSKI , PETAR OTKOVIC, DARIA ZUPN TADIJANOV \\ Department of Kinesiology, Faculty of Education, University of Josip Juraj Strossmayer, Osijek, Croatia
}

\begin{abstract}
The Karate, for a decade now, has undergone the adaptation of their rules with a tendency for greater attractiveness and media enthusiasm to the best impression on the audience and media at its first appearance at the Olympics (Tokyo 2020). Therefore, the aim of this paper is to establish the trend of differences in the technical-tactical indicators of karate kumite between Karate World Championships in Tokyo 2008 and Madrid 2018. There were 274 contestants in Tokyo, seniors aged 18 and over in 137 combat, and 24 contestants in 12 combat in Madrid consisted 48 variables of techniques and tactics. The data was based on the 149 DVD videos. The karate fighting parameters were compared using Mann-Whitney U test. Analyses were performed using MedCalc statistical software 10.4 (MedCalc software, Ostend, Belgium) and $\mathrm{P}$ value $<0.05$ were considered statistically significant. The results indicate that there is no statistically significant difference in 45 of 48 variables of technical tactical indicators between two championships. Three variables showed a statistically significant difference: Kizame Tsuki-not-scored in attack, Gyako Tsuki Jodan-notscored in counterattack and Gyako Tsuki Chudan-not-scored in attack. The results between the technical-tactical indicators of the karate fighting in the two world championships indicates that generally there are no significant differences, particularly in the score-based techniques. Hand-not-scored techniques performed in Madrid showed lower level of frequency. Reasons for such results were in karate rules changes and in the increase of the fight length from 3 to 4 minutes that most probably led to energy rationalisation of movement structure. In this way, it can be concluded that today's karate fighters are less active from the aspect of non-scored techniques, compared to karate fighters ten years ago. Non-scored techniques within the combining technical structures of karate combat are likely to contribute that kind of differences. Keywords: Performance indicators; World Karate Union.
\end{abstract}

Cite this article as:

Vidranski, T., Otkovic, P., \& Tadijanov, D.Z. (2019). Differences in technical-tactical indicators of Karate Kumite between the World Championship in Tokyo 2008 and Madrid 2018. Journal of Human Sport and Exercise, 14(5proc), S2470-S2479. doi:https://doi.org/10.14198/ihse.2019.14.Proc5.64

Corresponding author. Department of Kinesiology, Faculty of Education, University of Josip Juraj Strossmayer, Osijek, Croatia. E-mail: tvidranski@foozos.hr

Supplementary Issue: Summer Conferences of Sports Science. $8^{\text {th }}$ International Workshop and Conference of the International Society of Performance Analysis of Sport (ISPAS), 11-13 th of September 2019 (Budapest, Hungary).

JOURNAL OF HUMAN SPORT \& EXERCISE ISSN 1988-5202

(c) Faculty of Education. University of Alicante

doi:10.14198/jhse.2019.14.Proc5.64 


\section{INTRODUCTION}

Karate sport is one of the most popular martial arts today. According to the World Karate Federation (WKF), over twenty million people worldwide are involved in karate sport in any way. In the last twenty years, the rules of karate sports have changed significantly with the tendency to increase the intensity and attractiveness of competitive activity, with the basic goal of adjusting karate in relation to spectators (Jovanovic and Mudric, 2003). Such an adaptation of the rules, in addition to popularity, makes karate sport more acceptable to the media and the public, therefore removes the last obstacle of receiving karate sport in the Olympic family and making its first appearance at the Tokyo 2020 Olympic Games (according to the criteria of the International Olympic Committee). The different style of karate contest caused by the new scoring system ipon, nihon, sanbon and extending the duration of the contest significantly influenced the structural complexity of karate contest, which represents the basic set of information for successful modelling of technical-tactical training and the development of karate sport. Therefore, the adoption of these changes in recent years, with the application of new rules, tactical concepts and fighting style, has led to greater attractiveness, but also influenced new goals that are characterized by greater demands in the sport preparation technology in karate sport. The study of structural karate analysis, as a starting point for technical and tactical training, is a scientific aspect of analysing the functioning of a phenomenon that occurs at all levels of sports activity. The analysis of competitive efficiency factors is conducted with the aim of determining standard indicators of competitive efficiency, the performance of technical and tactical elements, defining content types according to the characteristics of technical and tactical performance, and to obtain correlations between predictor and criterion sets of variables measured in exact scientific papers, because it is these sets of variables that describe the success factors in sports. The possibility of prediction and recognition of certain phenomena is a basic aspiration that arises in all sciences and in all fields of research and to be able to predict what variables in karate fighting are crucial for success in the same is the peak of research in kinesiology. This makes it easier for the sports coaches, the athletes themselves and all those involved in the sport to understand the problems that arises in the prediction of success in karate sport. The idea that detailed statistical processing can produce a potential result before it was achieved and before the event itself happens that we know exactly what it takes to succeed / win shows how research in kinesiology has gone a long way. This approach makes it easier for karate coaches to grasp previous unknown in karate sport and leads to continuous improvement in athletes' performance in both karate disciplines (kumite and kata). Situational efficiency, that is, success in karate contest, depends greatly on the success of performing different movement structures, in different ways and from different distances. Karate practice must therefore have accurate information on the utilization of different motion structures in relationship to effectiveness in karate contest. In many cases, information has not significantly exceeded the level of speculation and empiricism, so it is necessary to focus the interest's number of researchers and to analyse the importance of different motion structures as well as the structure of situations in karate contest. Accordingly, there is a great need to identify technical and tactical indicators (Oliva et al., 2002). The space of technical and tactical analysis of karate contest, based on the identification and registration of standard and derived parameters of situational efficiency, has not been sufficiently explored. The analysis of sports competitions in an empirical way provides a complete overview of the technical and tactical features of competitors and sport contest. For this fact the reason might be in the structural complexity of karate combat, in the complexity of identifying technical and tactical elements that reflects on the justification, that is, the rationality and economy of time spent in similar methodological procedures. Modern software systems for monitoring situational efficiency parameters, such as DATAVOLLEY software (for example volleyball) or universal ones like DARTFISH software, are not sufficiently suitable and reliable for the requirements of structural analysis of karate contest. There are a small number of works in karate sport that contain information on realistic indicators of an athlete's technical and tactical effectiveness in situational conditions. Most studies in recent years indicate 
that the relationship between scientific achievement and the technical advancement of sport is a trend crucial for the development of elite sport, including karate sports.

\section{Performance indicators (PIs) in Karate sport}

Karate combat can be seen as a complex dynamic system consisting of two fighters of opposite interests and goals. The interest and purpose of fighter " $\mathrm{A}$ " is the same as that of fighter "B" but is opposite to each other. If fighter "A" performs the technique before fighter "B" is in the attack phase, and fighter "B", which performs the technique in response to the attack, is in the counterattack phase. The main objective of the fighter in the attack phase is to realize the derived technique as a point, and the fighter in the counterattack phase to prevent a fighter in the attack phase to realize the potentially scoring technique and to get himself into a favourable situation for the realization of his derived technique as scoring. Thus, sports competitions in which two opponents confront each other can be viewed as complex dynamic systems in which two opposing systems, two teams or two individuals confront each other (see Figure 1).

Both systems are determined by the level of ability, characteristics and knowledge of fighters, which they use to achieve the best result - victory. When two opponents confront in the competition, characteristic events occur. Events in karate fighting happens as a product of mutual actions and influence of karate technique, tactics, rules of battle, battlefields, communication with the trainer and strategies. Changes that occur in one of these parameters affect changes in the other parameter (Modified by Hernandez, 1987) that can be recognized and recorded, and show the degree of effectiveness of both teams or individuals. They show in which segments (elements) of sporting contest a team or individual achieves an advantage. In other words, they indicate the possible causes of the final result of that competition (according to Dizdar 2001).

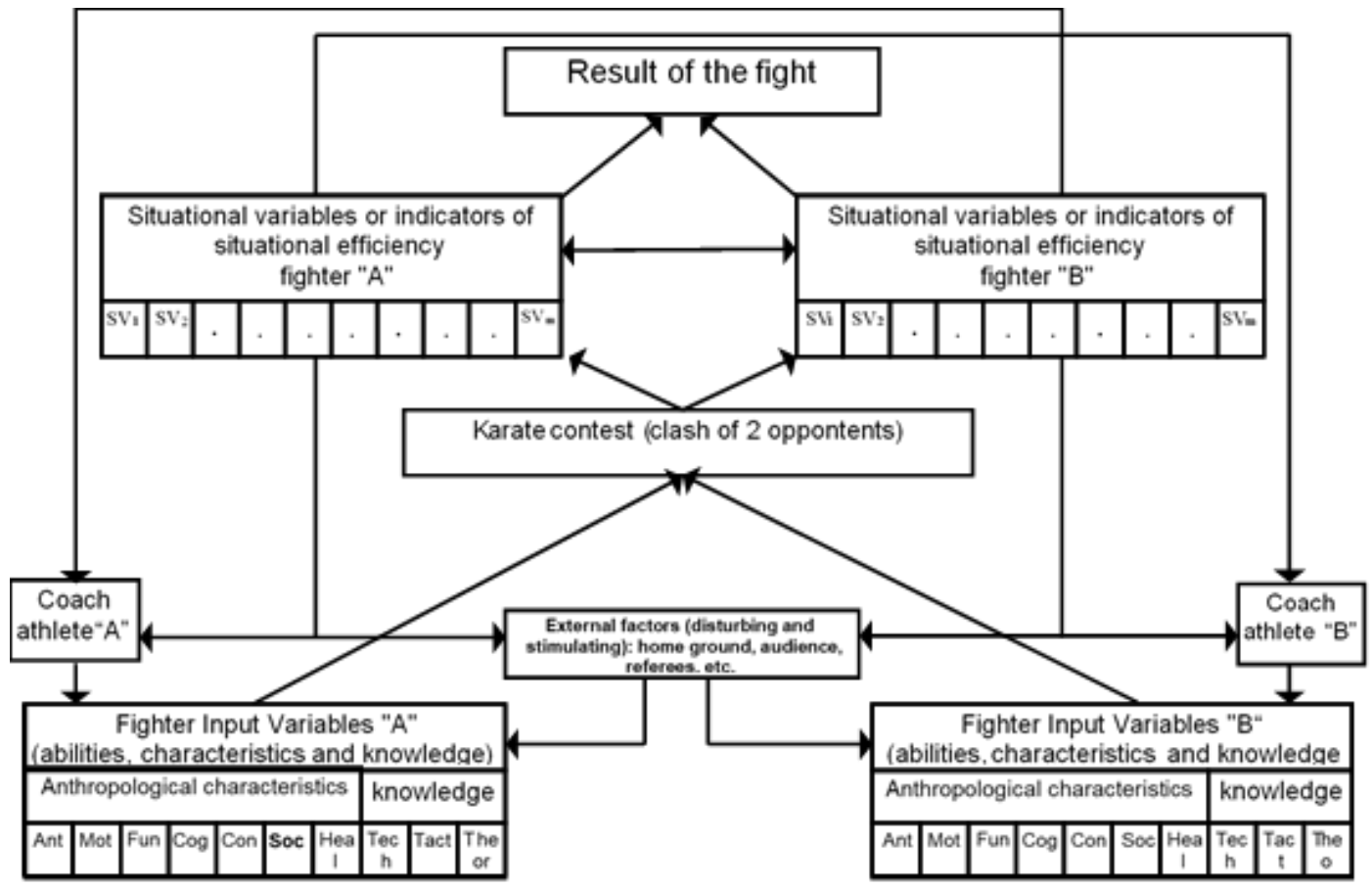

Legend: Ant - anthropometric or morphological characteristics. Mot - motor skills. Fun - functional abilities. Cog - cognitive abilities. Con - Connective features. Soc - sociological characteristics. Health - health status. Tech - Technical knowledge. Tact - Tactical knowledge. Theor - theoretical knowledge. SV - situational variables.

Figure 1. The interrelationships of the elements in a complex system of sport contest (modified by Dizdar 2001). 
Karate contest can be interpreted as an orderly set of activities that an individual fighter should perform in regard to the specifics of the opponent fighter, difficulty and level of competition, and within a particular concept of contest. There are various ways of performing combat activities which requires specific technical and tactical knowledge of how to implement something with a purpose of realizing (scoring) the performed activity (modified by Trninić, 1995). It is assumed that the indicators of technical and tactical efficiency in a sport fight are determined by the level of realization of activities that each fighter should perform given the characteristics of the opposing fighter, the difficulty and the level of competition. According to that, overall motor activity and behaviour of each individual athlete in attack and counterattack, depends on the objectives and implementation of specific activities during karate contest (see Figure 1). The question is which combat activities affect and how much they contribute to the final result of the fight. To determine the importance of the impact of each of these activities during karate contest, the performance of each athlete could be measured through the level of realization of each activity or series of activities. Therefore, it is possible to conclude that the concept of karate contest is achieved through successful performance of activities and objectified by means of indicators of situational efficiency (statistics of karate contest). Thus, activity in sports contest becomes measurable through situational (competitive) efficiency through technical-tactical indicators of situational efficiency in karate contest. On the basis of this, through technical and tactical indicators of situational efficiency, objective evaluation (positive and negative dimensions) of individual athletes and teams at karate competitions is possible. Considering that a considerable amount of information that an athlete emits in fights is contained in the summary event registration (frequency) of technical-tactical indicators, it can be assumed that the estimated athlete's situational effectiveness can be estimated by the method of derived condensation (summarization) of certain technical-tactical indicators of situational efficiency of the athlete. Therefore, in this paper, to evaluate the differences in the technical-tactical indicators in karate kumite between the Karate World Championships in Tokyo 2008 and Madrid 2018, a procedure (method) will be used to evaluate the analysed situational effectiveness of karate athletes on derived data to assess the situational effectiveness of karate athletes (according to Sertic, Vidranski, Szeged 2011).

\section{METHODS}

There were 274 contestants in Tokyo, seniors aged 18+ participating in over 137 combat, and 24 contestants in 12 combat in Madrid. Finally, research was consisted of 48 variables of techniques and tactics in karate. Participating athletes are contestants from 97 countries and five continents (Europe, Asia, Africa, Australia, America). The data was based on the 149 DVD videos.

The variable samples in this study are consisted of:

12 Descriptive Techniques and Tactics Variables: single technique not scored - attack (“TEH"na), single technique scored - attack ("THE"sa), single technique not scored - counterattack ("THE"nca), single technique scored - counterattack ("THE"sca).

1. Kizame tsuki (KT_na, KT_sa, KT_nca, KT_sca).

2. Gyaku tsuki jodan (GYJ_na, GYJ_sa, GYJ_nca, GYJ_sca).

3. Gyaku tsuki chudan (GYC_na, GYC_sa, GYC_nca, GYC_sca).

4. Mawashi geri chudan (MWC_na, MWC_sa, MWC_nca, MWC_sca).

5. Ashi mawashi geri chudan (AMWC_na, AMWC_sa, AMWC_nca, AMWC_sca).

6. Mawashi geri jodan (MWJ_na, MWJ_sa, MWJ_nca, MWJ_sca).

7. Ashi mawashi geri jodan (AMWJ_na, AMWJ_sa, AMWJ_nca, AMWJ_sca).

8. Ura mawashi geri jodan (UMWJ_na, UMWJ_sa, UMWJ_nca, UMWJ_sca).

9. Ashi ura mawashi geri jodan (AUMWJ_na, AUMWJ_sa, AUMWJ_nca, AUMWJ_sca). 
10. Ushiro mawashi geri jodan (UMWJ - na, UMWJ_sa, UMWJ_ncaUMWJ_sca).

11. Nage waza-tsuki (NWTS_na, NWT_sa, NWT_nca, NWT_sca).

12. Other technique (OT_na, OT_sa, OT_nca, OT_sca).

\section{RESULTS AND DISCUSSION}

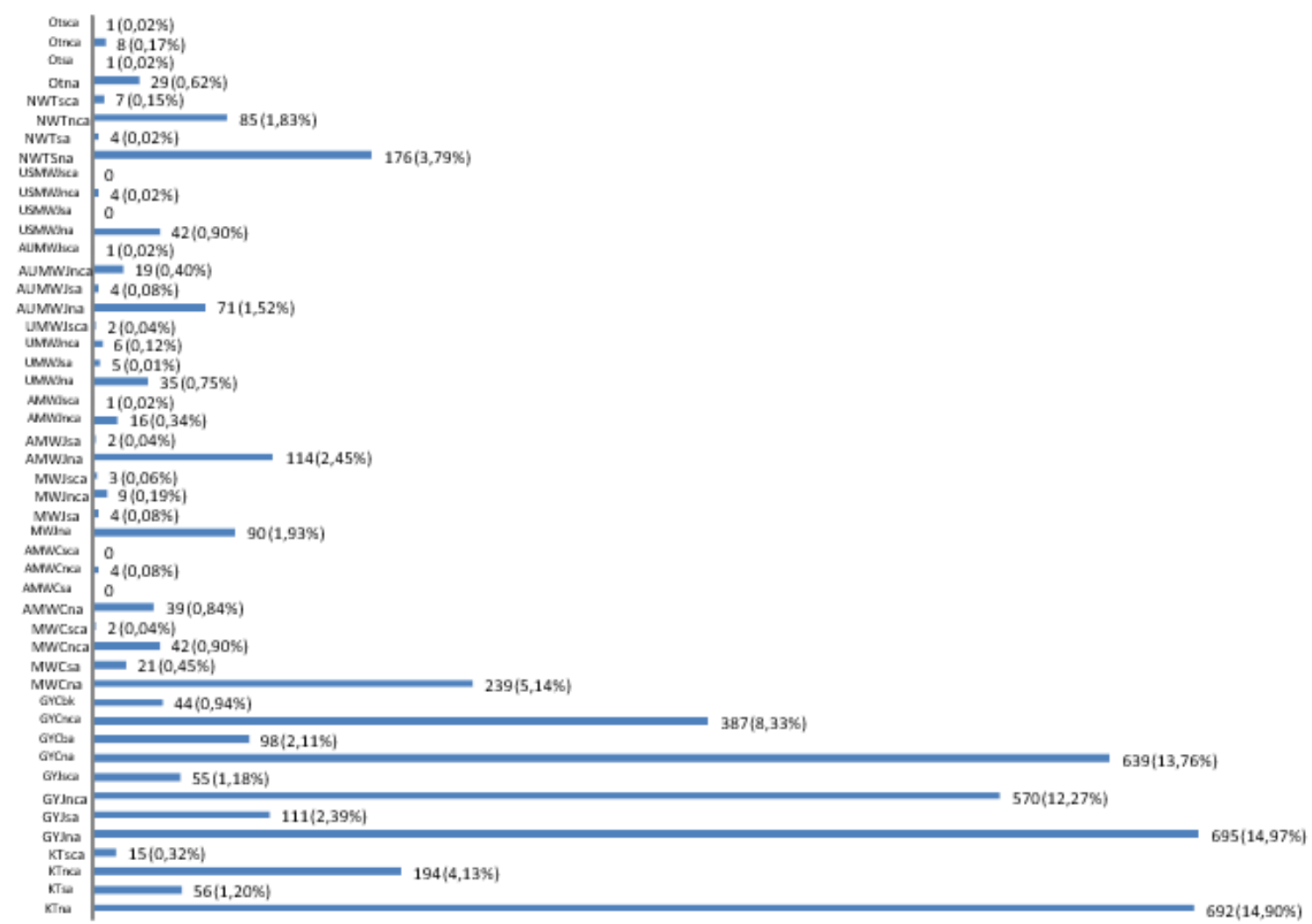

Figure 2. Total frequencies (\%) of scoring and non-scoring techniques during contest in Karate World Championships in Tokyo 2008.

The graph of total frequency (\%) of scoring and non-scoring techniques during contest in Karate World Championships in Tokyo 2008 (graph 1) shows prevailing dominance of only a few techniques in the total frequency of techniques. No scoring technique in attack gyaku tsuki jodan (GYJna) with a frequency of 695 non-scored techniques in 274 fights accounts for $14.97 \%$ of all techniques performed. This would mean that this technique represents every seventh technique in the totality of scoring and non-scoring techniques performed during contest. Given the fact that gyaku tsuki jodan technique has simpler biomechanical structure of motion and the great potential of combinatorics in multi-layered combinations as assumptions of various technical-tactical variations, such a great use value of this technique in combat is understandable. The same way we can explain technique Kizame tsuki's Offensive Attack (KTna) and his frequency of 692 reps or $14.90 \%$ in the total frequency of scoring and non-scoring techniques during contest. Namely, this technique is characterized by an even simpler biomechanical structure of motion compared to the gyaku tsuki technique, especially when starting multiple attack combinations from the point of using minimal motion amplitudes to achieve fast and accurate attacks in head. Such attacks necessarily cause the opponent's reaction to move or block, and thus allow the attacker a more favourable realization of the scoring technique, positioned in a multi-layered combination of attacks. A slightly lower frequency of 639 repetitions or $13.76 \%$ 
can be observed with the non-scored technique in attack gyaku tsuki chudan (GYCna). The scoring zone of the head makes the basic biomechanical difference in motion structure between the gyaku tsuki iodine (GYJna) technique and the gyaku tsuki chudan (GYCna). It is this difference in the scoring zone that is likely to influence the difference in the frequency of the techniques mentioned. Hand punches to the head (tsuki jodan) in the technical-tactical phase of an attack are more commonly used than hand punches to the body (tsuki - chudan) in terms of security and dominance of the athlete in attach phase. Specifically, punches to the head cause a more frequent reaction of blocking and movement techniques with the aim of avoiding a hit compared to the punches performed in the body's scoring zone. Non-scored technique in counterattack gyaku tsuki jodan (GYJnca) with a frequency of 570 non-scored techniques in 274 fights accounts for $12.27 \%$ of all performed techniques. Just like other punches to the head, this punch gives the fighter a sense of security and dominance in controlling the attacker's movement. Namely, if an attacker wants to score in the attack, he must shorten the distance, that is, the distance between himself and his opponent. By shortening the distance, the attacker comes at a disadvantage to effectively avoid counterattack of the opponent. Gyaku tsuki yodan in counterattack (GYJnca) is a blow with the opposite hand in relation to the front leg of the combat stance whose point-correct performance (stretched extremity) implies a slightly shorter distance and a lower centre of gravity of the attacker. It is this last one that is the most favourable situation for scoring a counter-attack technique because the attacker is then at a disadvantage to move quickly and reorganize his unsuccessful attack. In other words, because of biomechanical specificities, non - scoring technique in counterattack gyaku tsuki jodan (GYJnca) enables athletes to realize a scoring counterattack technique in conditions of a disadvantaged attacker with shortened distance and low centre of gravity. On the same technical and tactical principles, the frequency of the gyaku tsuki chudan counter-attack technique (GYCnca) of 387 reps or $8.33 \%$ in the total frequency of scoring and non-scoring techniques during karate contest can be explained. The difference in the significantly lower frequency of the gyaku tsuki chudan (GYCnca) technique can be explained by the biomechanical structure of the movement at which this impact ends up in the body. The lower frequency when using this technique in counterattack can be explained by the weaker reaction of the attacker from the point of psychological views and the effects of the reactions of movements and blocks from the hand punches. The highest frequency of leg techniques during karate contest is demonstrated by the non - scored technique in attack mawashi geri (MWCna) with a frequency of 239 or $5.14 \%$ of all scoring and non-scoring techniques performed during karate contest. Considering that this is the first leg, and only the sixth technique in terms of overall frequency of all techniques during karate contest, we cannot but notice the low representation of leg techniques compared to hand techniques during karate contest. Namely, generally speaking, the biomechanical complexity of leg techniques causes itself less use during contest. It is this semi-circular mawashi geri chudan (MWCna) leg technique that has a slightly simpler biomechanical structure of movement than other leg techniques covered in this research and which appears during karate contest. This is precisely one of the main arguments that can explain the highest utility value manifested by the frequency of $5.14 \%$ of all scoring and non-scoring techniques performed during karate contest. The fourth technique in terms of performance representation in the total frequency of scoring and non-scoring techniques during karate contest is the non-scoring hand counter-attack technique of Kizame tsuki (KTnca) at 194 frequencies or $4.13 \%$. This technique is used in counterattack as the second choice when talking about hand techniques because of the aforementioned competitive advantages of the gyaku tsuki technique, but also as a surprise technique at the beginning of an opponent's attack. Non - scoring technique in attack nage waza tsuki (NWTna) occurs with a frequency of 176 reps, or $3.79 \%$ of all scoring and non-scoring techniques in karate combat. This frequency of this combination in the total frequency can be explained by a maximum score of three points (sannon). Given the aforementioned and certain attractiveness of this combination, it still does not occupy a significant place compared to other performed techniques during karate contest. The reason for this is the very high biomechanical complexity of performing this technical combination in combat. In addition to the high complexity of this combination, there is also a 
high risk of counter-attacking movements. Following above, it is obvious from the analysis of the most performed techniques that the World Cup athletes did not want to take much risk.

Table 1. Results of the Mann-Whitney test of statistical significance of differences between Karate World Championships in Tokyo 2008 and Madrid 2018 in derived variables of situational efficiency.

\begin{tabular}{|c|c|c|c|c|}
\hline \multirow[t]{2}{*}{ Variable } & \multicolumn{2}{|c|}{$\bar{x}$ ranks } & \multirow[t]{2}{*}{$z$} & \multirow{2}{*}{$p$} \\
\hline & SP Tokyo 2008 & SP Madrid 2018 & & \\
\hline KTnaT & 128 & 88.2 & -2.49 & 0.0129 \\
\hline KTsaT & 27.64 & 30.1 & 0.41 & 0.684 \\
\hline KTncaT & 59.98 & 45.75 & -0.82 & 0.4131 \\
\hline KTscaT & 8.38 & 6.5 & -0.65 & 0.516 \\
\hline GYJnaT & 118 & 86.3 & -1.25 & 0.2124 \\
\hline GYJsaT & 28.6 & 28 & -0.09 & 0.9254 \\
\hline GYJncaT & 116.2 & 60.72 & -2.74 & 0.0061 \\
\hline GYJscaT & 26.22 & 22.5 & -0.42 & 0.6742 \\
\hline GYCnaT & 118.2 & 31.4 & -4.28 & 0.0001 \\
\hline GYCsaT & 40.7 & 31 & -0.59 & 0.5382 \\
\hline GYCncaT & 100.1 & 72 & -0.97 & 0.3322 \\
\hline GYCscaT & 21.6 & 19.5 & -0.24 & 0.8132 \\
\hline MWCnaT & 74.4 & 66.6 & -0.51 & 0.6114 \\
\hline MWCsaT & 10.7 & 9 & -0.38 & 0.7055 \\
\hline MWCncaT & 17.3 & 30 & 1.71 & 0.0881 \\
\hline AMWCnaT & 17.5 & 17.4 & -0.02 & 0.9806 \\
\hline MWJnaT & 34.2 & 25.5 & -0.97 & 0.3324 \\
\hline AMWJnaT & 35.9 & 37.2 & 0.1 & 0.9203 \\
\hline UMWJnaT & 16.7 & 14 & -0.39 & 0.6971 \\
\hline UMWJncaT & 3.7 & 4.8 & 0.95 & 0.5714 \\
\hline AUMWCnaT & 27.3 & 19.5 & -0.7 & 0.4838 \\
\hline UMWJnaT & 16.7 & 14 & -0.039 & 0.6971 \\
\hline UMWJncaT & 3.7 & 4.8 & -0.95 & 0.5714 \\
\hline NWTSnaT & 55.4 & 34 & -0.95 & 0.343 \\
\hline OTnaT & 15.3 & 13 & -0.51 & 0.6129 \\
\hline
\end{tabular}

A look at Table 1 reveals the results of the Mann-Whitney test of the statistical significance of differences between groups of athletes in derived variables of situational efficiency. The results indicate that there is no statistically significant difference $(p<, 05)$ in 45 of 48 variables of technical tactical indicators between two championships. Three variables showed a statistically significant difference: Kizame Tsuki-not-scored in attack, Gyako Tsuki Jodan-not-scored in counterattack and Gyako Tsuki Chudan-not-scored in attack. The results between the technical-tactical indicators of the karate fighting in the two world championships indicates that generally there are no significant differences, particularly in the score-based techniques. Handnot-scored techniques performed in Madrid showed lower level of frequency. Reasons for such results were in karate rules changes and in the increase of the fight length from 3 to 4 minutes that most probably led to energy rationalisation of movement structure. The fact that the athletes at the WC in Tokyo achieved higher values of arithmetic means in the above mentioned variables of situational efficiency than the athletes at the 
WC in Madrid also confirms higher values of the arithmetic mean of the ranks ( $\bar{x}$ ranks). This way, it can be concluded that the athletes between the two world championships were the most distinguished by the higher values of arithmetic means of the derived variables of situational efficiency of hand-performed punches and non-scoring techniques. Equally, if one considers overall variables that statistically significantly $(p<, 05)$ different groups of athletes in two world championships, a higher representation of variables that occurs in an attack can be observed. Out of a total of 3 derived variables that differentiate groups, 2 variables are structured as attack variables. Equally, it can be concluded that the above-mentioned variables, that is, non - scored techniques of kisame tsuki and gyako tsuki in athletes characterize the multilayer structures of combinations and the positions of scoring techniques within combinations during the attack and counterattack phase.

Non - scored techniques make up a large part of the structure of a combined technique frame. Each fight is characterized by a number of structures of combining techniques, the most significant of which are the structures that contain the scoring technique. The structure of combining techniques is determined by the goal they seek to achieve. Such combining reactions in during karate contest are most often characterized by athletes with well-trained automatic attacks and counterattacks on specific activities of the opponent. It is assumed that the existence of a larger base and a higher level of automation of combining techniques makes it more likely to achieve greater scoring efficiency during karate contest. According to the author, there is currently a great deal of tactical action during karate contest, which is achieved through multi-layered combinations of attack techniques and slightly less counterattack techniques. There are currently a large number of athletes characterized by multi-layered combinations with elaborate dominance of scoring technique as the dominant style of fighting. This way of technical-technical action especially comes to expression in the differences of counterattacks, which in Europe athletes are combined techniques, while Asian athletes uses individual techniques.

Quite often, these are some interception techniques that are performed in order to disable the final stage of the scoring punch. There are different possibilities of using interception techniques. Most of these techniques are achieved through the use of tactics to reduce the dynamics and structure of the upcoming attack, movements and blocks, followed by counter - scoring technique as the basic concept of fighting during karate contest. There is also a large group of preparation techniques (so-called fake techniques) with the aim of successfully positioning the scoring technique in time and space. These techniques are consisting of a large space of combined techniques which are very commonly used as a concept of fighting. These techniques, by their combining structure, influence the finding and creation of favourable spatiotemporal circumstances to achieve the scoring technique as the basic tactical concept of fighting during karate contest. The effectiveness of this concept depends primarily on the behaviour and reaction of the opponent. These results indicate that Tokyo WC athletes took more initiative during karate contest, made it easier to enter into opponent distances, were more dynamic and active than WC athletes in Madrid. The reasons for these results suggest that a change in karate rules, especially increasing the length of combat from 3 to 4 minutes in medal fights (WKF Rules, 2019), has most likely led to the energy rationalization of moving structures. Namely, according to some studies (Imamura et al., 2002; lide et al., 2008), hand punches are less demanding from the functional aspects of oxygen supply (VO2) and cardiac rhythm than other important structural units of karate. Another peculiarity of karate contest is the fact that athletes who succeed in spending energy more rationally (structurally more precisely and more efficiently) will have an advantage over their opponent. This may also be one of the reasons why frequencies of hand techniques are lower during WC Madrid after ten years of developing karate sports. Considering the dominance of highly intensive structural activities during the karate fight, which consequently use anaerobic metabolism as the predominant source of energy, by physiological classification and dominance of the energy processes, we can classify karate kumite as a 
lactate-glycolytic anaerobic sport (Lehmann and Jedliczka 1998; Schmidt and Perry 1976). These assumptions are based on two major studies, in which karate combat is set as a pattern of activity comparable to interval training (Lehmann and Jedliczka 1998). In another karate survey, karate contest was set as an activity pattern comparable with attempts to simulate 60 attacks, that is, continuous hand and foot attacks per minute (Backer and Bell 1990). The later activity pattern used in the aforementioned studies is somewhat different and it is shorter than the usual karate contest (Lehmann and Jedliczka 1998). Also, studies of assessing the functional capabilities of karate athletes performed during kata and kumite training (Francescato et al. 1995; Imamura et al. 2002, 2008; Shaw and Deutsch 1982; Zehr et al. 1997) are not comparable to real karate contest. According to recent research (Beneke et al. 2004), the structural profile of acyclic activity during karate contest suggests that aerobic metabolism is the predominant energy source with anaerobic supplementation, with mainly high phosphate-rich energy. According to the mentioned research, the functional basis of karate fighting is: $77.8 \%$ aerobic capacity, and $22.2 \%$ anaerobic capacity, of which $16 \%$ ATP (adenosine triphosphate) - PC (keratin phosphate), and $6.2 \%$ anaerobic glycolytic capacity. All cited indicators of the energy profile during karate contest indicate that rationalization of movement, which is a consequence of lower frequency of performed techniques, can most likely lead to greater energy potential for performing higher-scoring techniques. This fact can explain the reason for the lower frequency of hand techniques between the two karate world championships.

In this way, it can be concluded that today's athletes are less active from the point of view of non-scored techniques than the karate athletes ten years ago from energy rationalization of movement point of view.

\section{CONCLUSION}

The results of the Mann-Whitney test of the statistical significance of the differences between the technical and tactical indicators of karate contest at two world championships within 10 years indicate that there are generally no significant differences, especially in scoring techniques. Differences were made with the lower level of frequencies of non-scoring hand techniques, which were made during karate contest at the 2018 World Cup in Madrid. The reasons for these results suggest that a change in karate rules, especially increasing the length of fight from 3 to 4 minutes in medal fights (WKF Rules, 2019), has most likely led to the energy rationalization of moving structures. In this way, it can be concluded that today's athletes are less active in terms of performing non-scored techniques than karate athletes ten years ago. This difference is probably due to the non - scored techniques within the combining technical structures of karate contest.

\section{REFERENCES}

Baker, J.S., Bell, W. (1990). Energy expenditure during simulated karate competition. Journal of Human Movement Studies, 19, 69-74.

Beneke, R., Beyer, T., Jachner, C.; Erasmus, J.; Hutler, M. (2004). Energetics of karate kumite. European Journal of Applied Physiology, 92(4-5), 518-523. https://doi.org/10.1007/s00421-004-1073-x

Dizdar, D. (2001). Vrednovanje skupa metoda za procjenu stvarne kvalitete košarkaša. (Doktorska disertacija, Sveučilište u Zagrebu). Zagreb: Fakultet za fizičku kulturu Sveučilišta u Zagrebu. https://doi.org/10.15255/kui.2017.048

Francescato, M.P., Talon, T.; Di Prampero, P.E. (1995). Energy cost and energy sources in karate. European Journal of Applied Physiology, 71, 355-361. https://doi.org/10.1007/bf00240417

Hernandez, J. (1987). Estudio sobre el analisis de la accion de juego en los deportes de equipo su aplicacion al balancesto. (Doctoral thesys, Facultad de filosofia y ciencias de la educacion). 
Barcelona: Facultad de filosofia y ciencias de la educacion. https://doi.org/10.4067/s071845652011000200011

lide, K., Imamura, H., Yoshimura, Y., Yamashita, A., Miyahara, K., Miyamoto, N., Moriwaki, C. (2008). Physiological responses of simulated karate 250 sparring matches in young men and boys. Journal of Strength and Conditioning Research, 22(3), 839-844. https://doi.org/10.1519//sc.0b013e31816a5af6

Imamura, H., Yoshimura, Y., Nishimura, S., Nakazawa, A. T., Teshima, K., Nishimura, C., Miyamoto, N. (2002). Physiological responses during and following karate training in women. Journal of Sports Medicine and Physical Fitness, 42(4), 431-437.

Jovanović, S., Mudrić, R. (2003). Analysis of rule changes in judging in karate from the aspect of frequency of pointing techniques, Collection of works Science and Karate sport, Karate Federation of Vojvodina, 4, 24-29.

Lehmann, G., Jedliczka, G. (1998). Investigations about the event specific profile of karate. Leistungssport, 28(3), 56-61.

Oliva, A. S., Torres, F. B., Navarro, J. M. (2002). Diseno Grafico Am 2000, Combate Supremo.

Sertić, H., Vidranski, T., Segedi, I. (2011). Evaluation of a method for objective assessment of situational effect in karatekas through technical-tactical indeks for situational efficiency. In Pass.com: Proceedings Book, «Integrative power of Kinesiology» 6th international scientific conference (edited by D. Milanović, And G. Sporiš), pp. 651-656. Opatija, Croatia: Faculty of Kinesiology, University of Zagreb.

Shaw, D.K., Deutsch, D.T. (1982). Heart rate and oxygen uptake response to performance of karate kata. Journal of Sports Medicine, 22, 461-468.

Trninić, S., D. Milanović, M. Blašković, Ž. Birkić, D. Dizdar. (1995). Utjecaj skokova u obrani i napadu na konačan rezultat košarkaške utakmice. Kineziologija, 27 (2), 44-49.

Zehr, E. P., Sale, D. G., Dowling, J. J. (1997). Ballistic movement performance in karate athletes. Medicine \& Science in Sports \& Exercise, 29(10), 1366- 1373. https://doi.org/10.1097/00005768$199710000-00014$

World Karate Federation (2019). Downloaded September 10, 2019. http://www.wkf.net/index.php?option=com_content\&view=article\&id=89\&ltemid=93

Wkf Rules Regulations And Commissions (2010). Downloaded June 20, 2010. http://www.wkf.net/images/stories/downloads/wkf_rules_regulations_and_commissions_eng.pdf

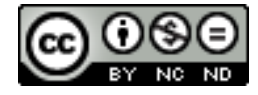

This work is licensed under a Attribution-NonCommercial-NoDerivatives 4.0 International (CC BY-NC-ND 4.0). 